\title{
Effect of Detergents on Quality and Flavor of Fresh-Cut Mint
}

\author{
Chao Zhang ${ }^{\mathrm{a}}$, Yunfei $\mathrm{Li}^{\mathrm{b}}$, Yubin $\mathrm{Wang}^{\mathrm{c}}$, Yue Ma ${ }^{\mathrm{d}}$, Xiaoyan Zhao ${ }^{\mathrm{e}}$
}

Beijing Vegetable Research Center, Beijing Academy of Agriculture and Forestry Sciences; Beijing Key Laboratory of Fruits and Vegetable Storage and Processing; Key Laboratory of Biology and Genetic Improvement of Horticultural Crops (North China), Ministry of Agriculture; Key Laboratory of Urban Agriculture (North), Ministry of Agriculture, 9 Shuguanghuayuan Road, Haidian District, Beijing, China

azhangchao@nercv.org, ${ }^{b}$ liyunfei@nercv.org, ${ }^{c}$ wangyubin@nercv.org, ${ }^{d}$ mayue@nercv.org, 'zhaoxiaoyan@nercv.org

Keywords: fresh cut, mint, detergents, flavor, sensory

Abstract. The effect of detergents on the quality of fresh-cut mint was evaluated. The acidic electrolyzed water and sodium hypochlorite extended the shelf life of the fresh-cut mint to $12 \mathrm{~d}$ and maintained its flavor. The Sodium hypochlorite treatments avoid the loss of the greenness of the mint. Hence, the sodium hypochlorite was a better detergent for the production of fresh-cut mint.

\section{Introduction}

Mint (Mentha spicata L.) is one of the popular Thai kitchen herbs due to its unique aroma and benefits to human health such as helping to relieve from colds, flu, fever, motion sickness and poor digestion problems [1, 2]. Mint is refreshing, antiseptic, anti-asthmatic, stimulative, diaphoretic, stomachic, and antispasmodic, which can be used as a medicinal and aromatic plant [1]. Meanwhile, mint is used in a variety of dishes such as vegetable curries, mint leaves recipe for chutney, fruit salads, vegetable salads, salad dressings, soups, desserts, juices, sherbets, etc [3, 4]. Hence, the demand of the fresh-cut mint increased quickly in the past decade [5].

The detergents, such as the acidic electrolyzed water and sodium hypochlorite, have been widely applied for sterilization of the fresh-cut vegetable[6-9]. However, the comparison of acidic electrolyzed water and sodium hypochlorite on the quality and flavor of the fresh-cut mint was not found to the best of our knowledge. Hence, the acidic electrolyzed water and sodium hypochlorite were applied as the detergents to sterilize the fresh-cut mint. The shelf life, quality and flavor of the treated mint were compared.

\section{Material and Methods}

Preparation of fresh-cut mint. Mint was picked from our Tongzhou farm (Tongzhou District Beijing, 2014) and was stored at $4{ }^{\circ} \mathrm{C}$ before use. The mint was washed by the tap water at $4{ }^{\circ} \mathrm{C}$ to remove the soil and inclusions, and then stirred at $680 \mathrm{rpm}$ for $2 \mathrm{~min}$.

Control: the washed mint was washed by water again for $5 \mathrm{~min}$ at $4{ }^{\circ} \mathrm{C}$ and was cut manually. The cut leaf of about $15 \mathrm{~g}$ was packaged in a $20 \mathrm{~cm} \times 18 \mathrm{~cm}$ polythene film and stored at $4{ }^{\circ} \mathrm{C}$.

Acidic electrolyzed water: the washed mint was sterilized by acidic electrolyzed water for 5 min at $4{ }^{\circ} \mathrm{C}$ and was cut manually. The cut leaf of about $15 \mathrm{~g}$ was packaged in a $20 \mathrm{~cm} \times 18 \mathrm{~cm}$ polythene film and stored at $4{ }^{\circ} \mathrm{C}$.

Sodium hypochlorite: the washed mint was sterilized by sodium hypochlorite of $100 \mathrm{ppm}$ for 5 min at $4{ }^{\circ} \mathrm{C}$ and was cut manually. The cut leaf of about $15 \mathrm{~g}$ was packaged in a $20 \mathrm{~cm} \times 18 \mathrm{~cm}$ polythene film and stored at $4{ }^{\circ} \mathrm{C}$.

Determination of chlorophyll by spectrophotometry. To measure the chlorophyll content, $20 \mathrm{ml}$ of $80 \%$ acetone was added to $5 \mathrm{~g}$ of each sample and mixed with a homogenizer (IKA T10 Basic, Werke GmbH \& Co. KG, Staufen, Germany) for $1 \mathrm{~min}$ at a high speed, then centrifuged at 8,000 rpm for $5 \mathrm{~min}$ at $4{ }^{\circ} \mathrm{C}$, and then filtered through Whatman No. 1 filter papers. The volume was adjusted to $25 \mathrm{~mL}$ and the absorbance values were measured at 663 and $645 \mathrm{~nm}$ by a spectrophotometer (UV-1800, Shimadzu Corporation, Kyoto, Japan). The chlorophyll content of the sample was calculated followed by Equation 1. 


$$
\text { Chlorophyll }=\frac{\left(20.2 \times A_{645}+8.02 \times A_{663}\right) \times D}{1000}
$$

where chlorophyll content is $\mathrm{mg} / \mathrm{g}$ fresh weight; $A_{645}$ and $A_{663}$ are the absorbance at $645 \mathrm{~nm}$ and $663 \mathrm{~nm}$, respectively; $D$ is the dilution factor of the sample.

Total microflora counts. Samples were serially diluted, plated in total count agar for total microflora counts, followed the recently reported method [10]. The plates were incubated at $37^{\circ} \mathrm{C}$ for $48 \mathrm{~h}$ and counted manually.

Flavor comparison. The flavor of the samples was compared by an electronic nose PEN2 (Airsense Analytics GmbH, Schwerin, Germany). The electronic nose was turned on for 30 min and flushed the testing system for $180 \mathrm{~s}$. The sample of $2 \mathrm{ml}$ was put in the testing tube. And then the electronic sensor was put into the testing tube to collect the results for $60 \mathrm{~s}$. The response of the sensor in 48 52 s were evaluated by a principal component analysis.

Statistical Analysis. Analysis of variance (ANOVA) was used to compare mean differences of the results. If the differences in mean existed, multiple comparisons were performed using Duncan's Multiple Range Test. All analysis was conducted using SPSS for Window Version 19. All experiments were done in triplicates or more.

\section{Results and Discussion}

Effect of detergents on shelf life of fresh-cut mint. The effect of detergents on the total micorflora count of fresh-cut mint is shown in Figure 1. The total microflora count of the Acidic electrolyzed water and Sodium hypochlorite treatments was not detected and marked as 0 in 0 and $3^{\text {rd }} \mathrm{d}$, which was lower than 2.0 LogCFU/g in fact. During the storage, the total microflora count of the Acidic electrolyzed water and Sodium hypochlorite treatments was significant lower than that of the control. Specifically, the total microflora count of the Acidic electrolyzed water and Sodium hypochlorite treatment exceeded the $5.0 \mathrm{LogCFU} / \mathrm{g}$ in the $12^{\text {th }}$ day, while that of the control exceeded in the $6^{\text {th }} \mathrm{d}$. Consequently, the Acidic electrolyzed water and Sodium hypochlorite treatment extended the shelf life of the fresh-cut mint for $6 \mathrm{~d}$.

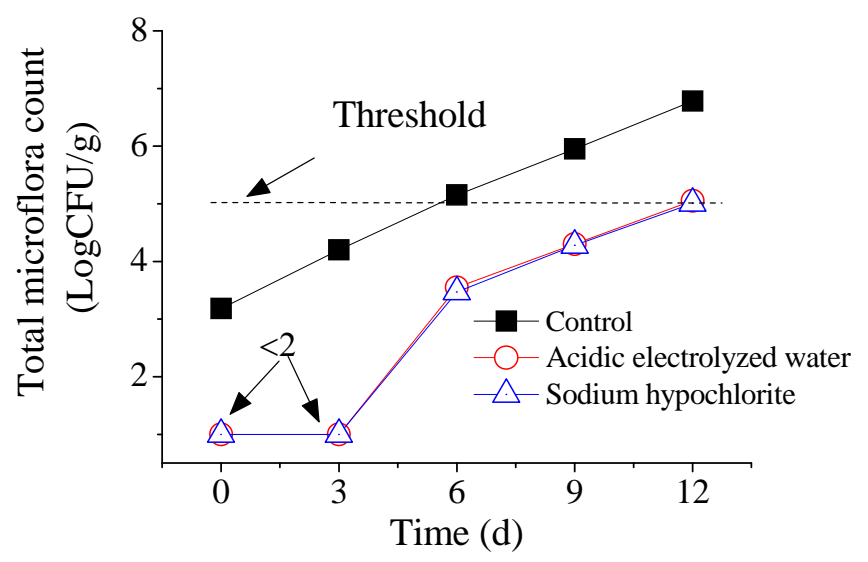

Figure 1 Effect of detergents on the total micorflora count of fresh-cut mint

Effect of detergents on chlorophyll content of fresh-cut mint. The effect of detergents on the chlorophyll content of the fresh-cut mint was compared (Figure 2). The chlorophyll content of the fresh mint was significantly reduced after each treatment. The chlorophyll content of the Sodium hypochlorite treatment treatments was similar to that of the control; while the chlorophyll content of the Acidic electrolyzed water treatment was lower than that of the control. Being different to our result, the chlorophyll content of the fresh-cut mizuna baby leaves is well preserved after shelf life [11]. In summary, the chlorophyll content of the fresh-cut mint was preserved by the Sodium hypochlorite treatment. 


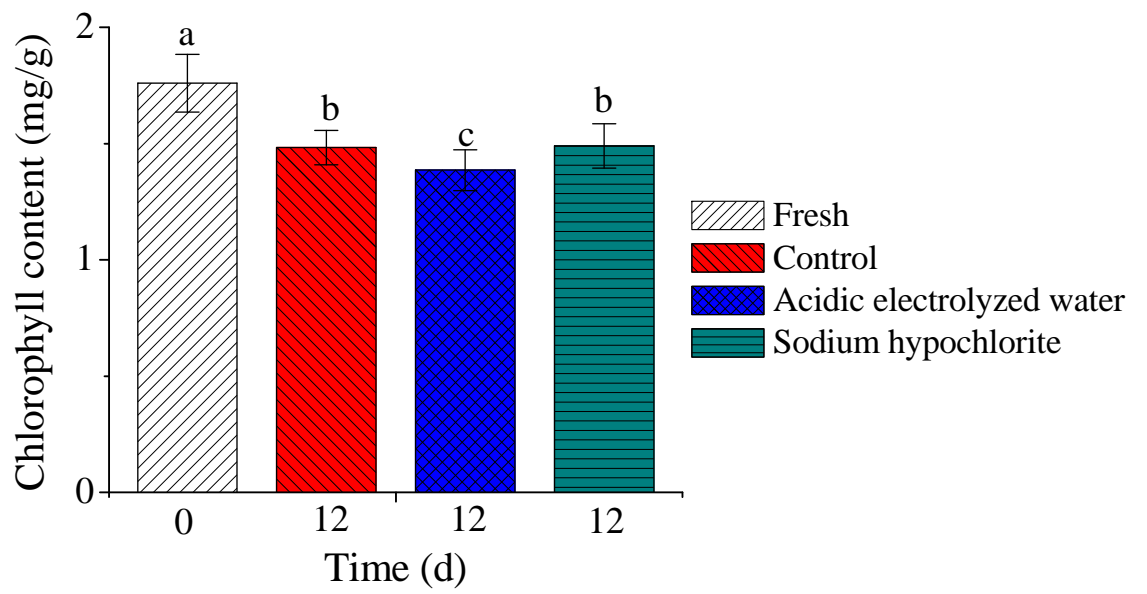

Figure 2 Effect of detergents on the chlorophyll content of fresh-cut mint

Effect of detergents on flavor of fresh-cut mint. The effect of detergents on the flavor of the fresh-cut mint is shown in Figure 3. The variance of the main component 1 and main component 2 was $98.88 \%$ and $1.06 \%$, respectively. The sum of the main component 1 and 2 accounted $99.94 \%$. Consequently, the component 1 and component 2 was effective to reflect the flavor of the mint. Remarkably, each treatment leaded to a significant flavor variety compared with the fresh mint. Tthe flavor of the Acidic electrolyzed water and Sodium hypochlorite treatments was similar to that of the control. Hence, the Acidic electrolyzed water and Sodium hypochlorite treatment showed no significant influence on the flavour of the fresh-cut mint.

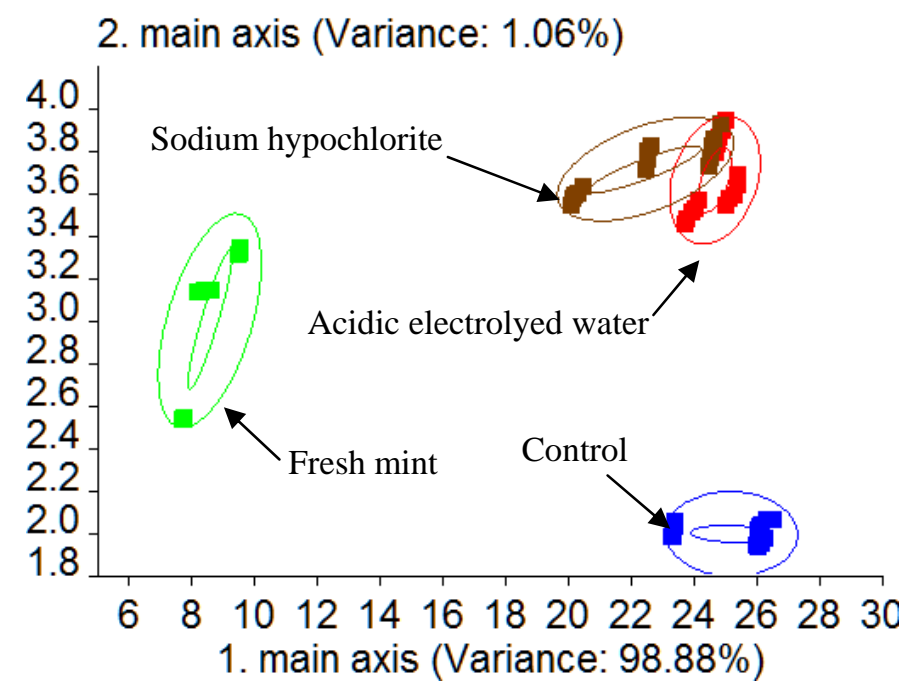

Figure 3 Effect of detergents on the flavor variety of fresh-cut mint

Effect of detergents on appearance of fresh-cut mint. The effect of detergents on the appearance of the fresh-cut mint is shown in Figure 4. The fresh mint shrank due to the stored at $4{ }^{\circ} \mathrm{C}$ for more than $20 \mathrm{~h}$. The stem of the mint became darker after being stored for $12 \mathrm{~d}$, which reflected the senescence of the mints. Remarkably, the control turned a little yellow, while the Acidic electrolyzed water and Sodium hypochlorite treatment preserved the original greenness of the mints. The increase of the microorganism could be one reason responding to this phenomenon, when the microorganism of the control was significantly enhanced comparing with that of the Acidic electrolyzed water and Sodium hypochlorite treatments. 

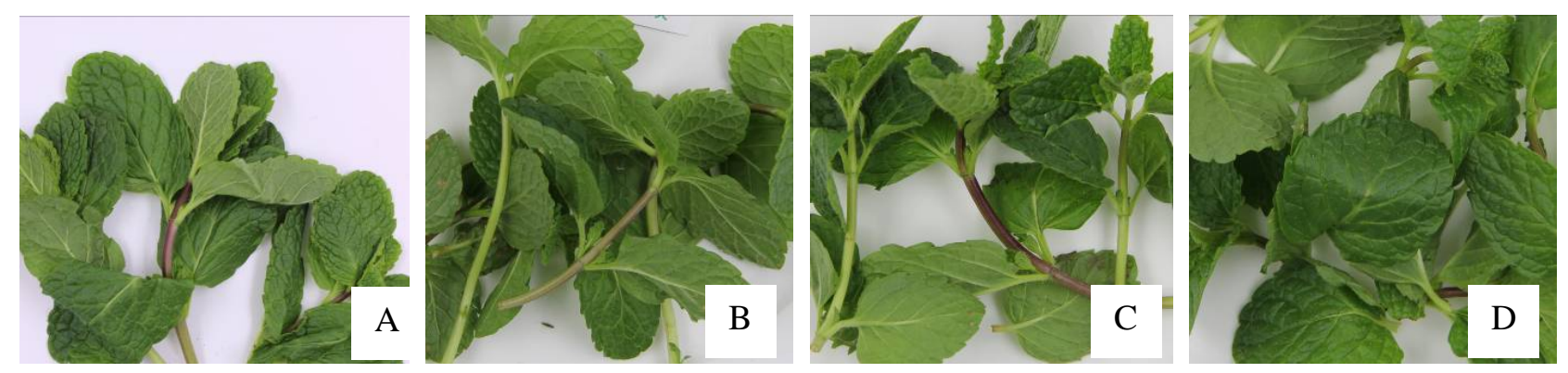

Figure 4 Appearance of the fresh mint (A), Control (B), Acidic electrolyed water (C),

and Sodium hypochlorite (D)

\section{Conclusions}

The acidic electrolyzed water and sodium hypochlorite extended the shelf life for $6 \mathrm{~d}$. The Acidic electrolyzed water and Sodium hypochlorite treatments were effective to maintain the flavor of the fresh-cut. The Sodium hypochlorite treatments avoid the loss of the greenness of the mint. Hence, the sodium hypochlorite was a better detergent for the production of fresh-cut mint.

\section{Acknowledgements}

The authors are grateful to financial support of the earmarked fund for Modern Agro-industry Technology Research System (CARS-26-22 \& CARS -25), Beijing Academy of Agricultural and Forestry Sciences, New Discipline Breeding (KJCX20140204) and Beijing Key Laboratory of Fruits and Vegetable Storage and Processing (Z141105004414037).

\section{References}

[1] B. Ozbek, G. Dadali: J. Food Eng. Vol 83 (2007) 541.

[2] N. Therdthai, W. Zhou: J. Food Eng. Vol 91 (2009) 482.

[3] K. Jin Park, Z. Vohnikova, F. Pedro Reis Brod: J. Food Eng. Vol 51 (2002) 193.

[4] A. K. Thompson, Fruits and vegetables (2nd Ed.), Blackwell Publishing, Oxford 2003.

[5] J. Santos, M. Herrero, J. A. Mendiola, M. T. Oliva-Teles, E. Ibanez, C. Delerue-Matos, M. B. P. P. Oliveira: LWT Vol 59 (2014) 101.

[6] S. Koide, J.-i. Takeda, J. Shi, H. Shono, G. G. Atungulu: Food Control Vol 20 (2009) 294.

[7] S. Koide, D. Shitanda, M. Note, W. Cao: Food Control Vol 22 (2011) 452.

[8] S.-Y. Lee, S.-Y. Baek: Food Microbiol. Vol 25 (2008) 582.

[9] S. Szczepanski, A. Lipski: Food Control Vol 36 (2014) 224.

[10]A. Rivasa, D. Rodrigoa, A. Martíneza, G. V. Barbosa-Cánovasb, M. Rodrigo: LWT Vol 39 (2006) 1163.

[11]A. Tomas-Callejas, G. B. Martinez-Hernandez, F. Artes, F. Artes-Hernandez: Postharvest Biol. Technol. Vol 59 (2011) 298. 